\title{
Practice of urinary catheterization and knowledge in junior staff: a quality control study
}

\author{
This article was published in the following Dove Press journal: \\ Clinical Audit \\ 30 July 2012 \\ Number of times this article has been viewed
}

\section{Muhammad R Cheema \\ FR Shuaib \\ JA Barrett \\ Wirral University Teaching \\ Hospital, Wirral, UK}

Correspondence: Muhammad Raza

Cheema

Flat 25-C Riverview, 174 Arrowe Park

Road, Woodchurch, Wirral,

Merseyside, UK

Tel +4475 7244 I537

Email drmrcheema@hotmail.com
Abstract: Our study was conducted in the inpatient setting of Department of Elderly Medicine. A high percentage of indwelling catheters at discharge had been observed. Our study aimed to ascertain whether these catheters were being placed for appropriate indications. Catheter placement is performed by junior doctors and nurses in the ward, therefore their knowledge of guidelines regarding indications, procedure, and documentation for catheterization and its complications was deemed to be a vital factor in determining the incidence of long-term catheter placement. A questionnaire was administered to carry out a cross-sectional survey of normal practice and opinion regarding long-term catheter placement.

Keywords: catheter, catheterization, indications

Our study revealed that $89.6 \%$ of total catheterizations (short term and long term) over the two-week study period were performed with complete documentation and for appropriate indications as per the Infectious Diseases Society of America (IDSA) guidelines. Indication for catheterization was not documented in $10.4 \%$ of cases.

\section{Objectives}

- To ascertain whether catheters were being placed for appropriate indications as per IDSA guidelines. ${ }^{1}$

- To appraise the knowledge of working staff regarding indications, complications and procedural documentation of catheterization.

\section{Background}

Indwelling catheters have become a familiar feature in the elderly population; their placement is aimed to relieve obstructive urinary symptoms when other interventions are not feasible. Despite their symptomatic benefit they are often implicated in causing recurrent urinary tract infections, discomfort and retention resulting from catheter blockage, and are associated with an increased frequency of readmission. Their benefit versus morbidity ratio has to be balanced very carefully depending upon clinical opinion and individual patient scenarios. Recurrent urinary tract infections result in the need for antibiotic administration, which ultimately facilitates the emergence of drug-resistant bacteria. Long-term catheter-associated urinary tract infections (UTIs) substantially account for global disease burden. ${ }^{1}$

According to recent data, catheter-associated (CA) bacteriuria has been found to be the number one health-care-associated infection worldwide. ${ }^{1}$ This is a direct 
consequence of the prevalent use of urinary catheterization in inpatient settings in hospitals as well as long-term care facilities (LTCFs). Some of these catheter placements are indiscriminate and add to the cost and personnel resources expended by the hospital.

Ensuring that guidelines for catheter placement are comprehensive, clear, and precisely followed would result in a decrease in the overall number of long-term catheter placements and consequently a decrease in the associated morbidity burden.

Our quality control study was conducted in the Department of Elderly Medicine (DME) setting. This setting was chosen after the observation that a large number of patients were being discharged with long-term urinary catheters. We decided to assess if long-term catheter placement was for the right indication. Junior doctors and nurses in the ward usually carry out catheterization so we also performed a cross-sectional survey of their knowledge regarding indications and complications of urinary catheterization. It was anticipated that in some cases ambiguous documentation as to why the catheter was placed and a lack of follow-up instructions may have the consequence of the catheter staying in the patient for a prolonged period.

\section{Methods}

Data were collected over a period of two weeks from the DME. Approval to conduct this study was obtained from the local Risk Management and Governance department. All patients aged over 70 years with catheters were included in this study.

Medical notes were used to identify the indications for catheterization and to assess proper documentation pertaining to procedure of catheterization. This documentation comprised date, time, indication of catheterization, personnel name, catheter size, volume and color of urine drained, use of aseptic technique and antibiotic prophylaxis given.

A questionnaire survey was carried out to evaluate the knowledge among the staff regarding catheterization indications, complications, and documentation. The questionnaire was administered to the junior doctors during the weekly teaching sessions on an optional basis. Ward managers distributed questionnaires to nursing staff who were trained in urinary catheterization. Out of a total of 80 potential staff members, the questionnaire was administered to 40 with a $100 \%$ response rate.

A sample of the data collection sheet is presented in Appendix 1, and the questionnaire survey in Appendix 2.

\section{Results}

The majority $(85.3 \%)$ of the patient cohort were aged 76-90 years (Figure 1). Forty completed questionnaires were collected from nurses and junior trainee doctors (foundation year 1 and 2) to appraise their knowledge of indications, complications, and procedural documentation of catheterization. The results are as follows:

- Documentation of the date of procedure, personnel doing the procedure, the indication for catheterization use of aseptic technique: 100\% agreed (Figure 2).

- Document if prophylactic antibiotics were given and if a sample was sent for analysis: $77 \%$ agreed.

- Document the volume of urine drained: $97.4 \%$ agreed. $89.7 \%$ agreed they would document a description of the urine drained and 87\% acknowledged they would document if it was a difficult procedure.

A total of 61 patients had indwelling catheters during the 2 weeks of data collection. A catheter was in place at admission in $21.4 \%$ of these patients. The remaining had catheters placed during the hospital study. Indications for catheterization (Figure 3) were as follows: retention of urine, 36.1\%; chronic incontinence, $8.2 \%$; incontinence with pressure sores, $27.9 \%$; strict fluid balance charting, $6.5 \%$; to obtain a sample of urine, $1.6 \%$; indication for catheterization not clear from documentation, $10.4 \%$. Indications according to IDSA guidelines were observed in $89.6 \%$ of the patients who had catheters placed during the hospital study.

Table 1 shows the demographics and common comorbidities of the cohort. Table 2 shows the results in tabulated form comparing the practice observed and awareness of proper documentation of catheterization procedure.

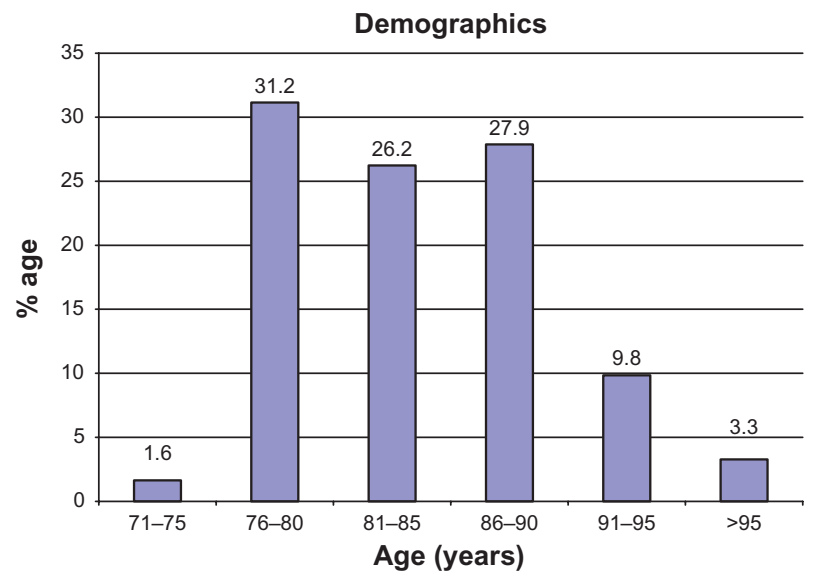

Figure I The age range of patients included in the study; $85.3 \%$ of the patients were aged between 76-90 years. 


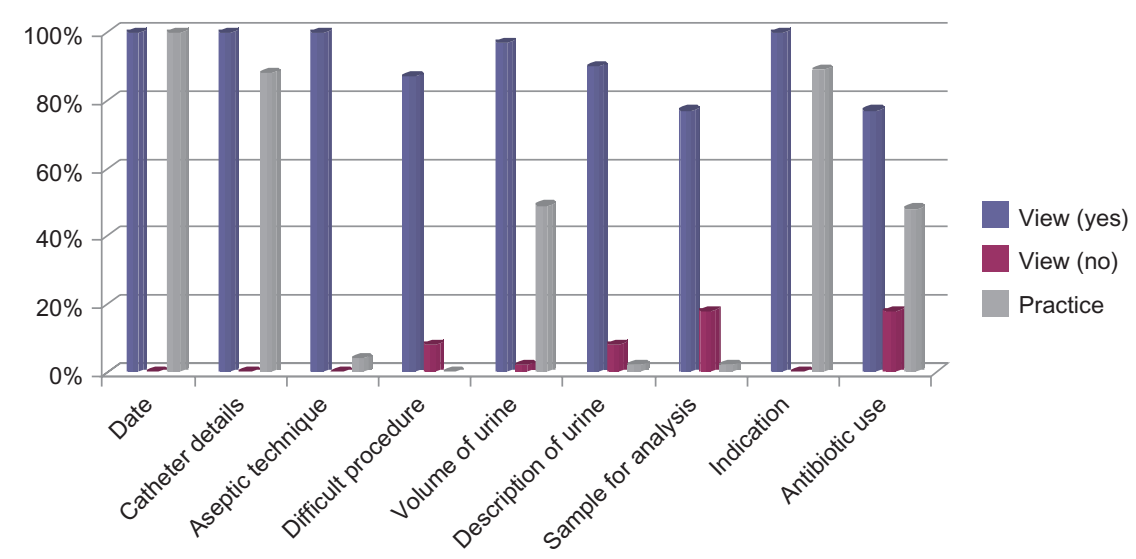

Figure 2 The views of junior doctors and nursing staff regarding appropriate documentation compared with the current practice of documentation after a urinary catheter has been inserted.

Notes: Yes, should be documented; No, should not be documented; Practice, currently being practiced/documented in notes.

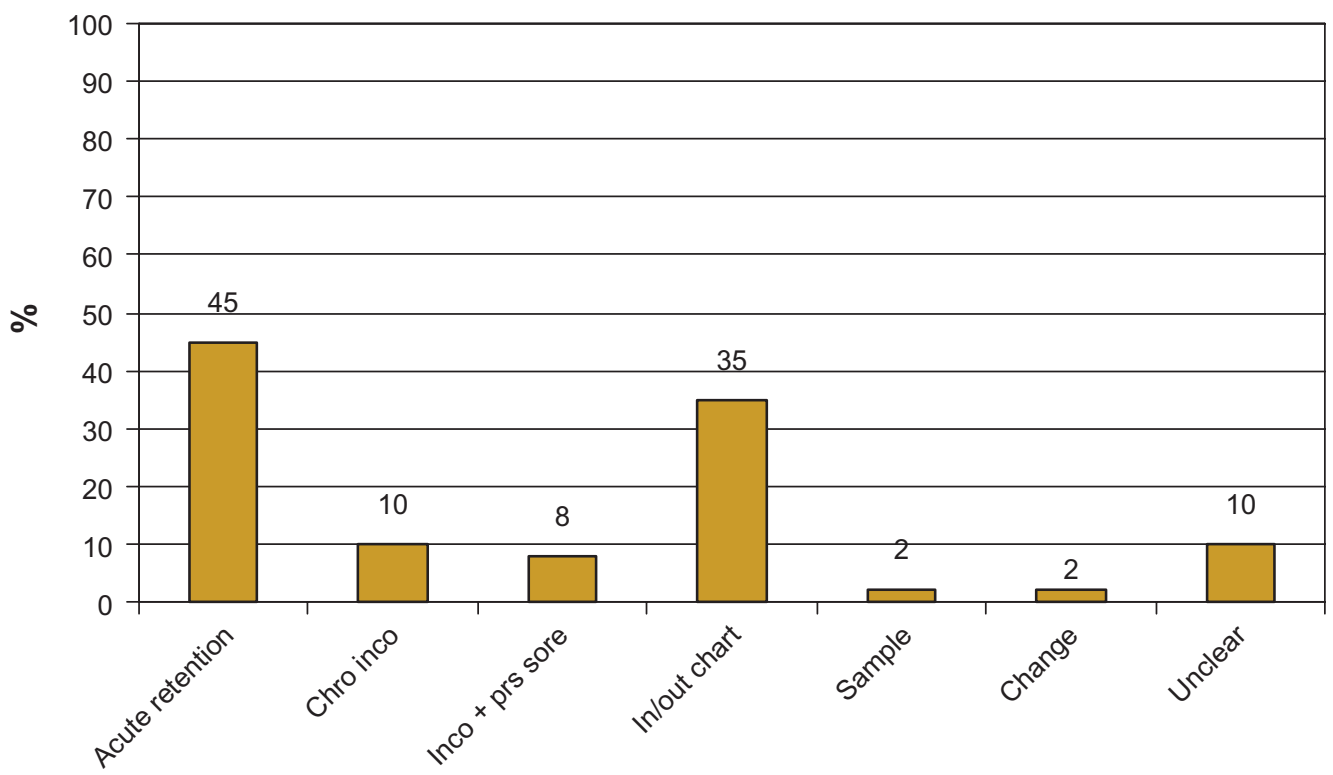

Figure 3 The percentages of patients catheterized for the following indications: chronic incontinence (Chro inco), incontinence with pressure sores (Inco + prs sore), urinary output monitoring (In/out chart), catheterization to obtain urine sample (Sample), new catheters inserted for long-term catheter patients (Change), or indication unclear/ not documented (Unclear).

Table I Demographics of the group, including the number of patients that were admitted with long-term catheter and common comorbidities

\begin{tabular}{lll}
\hline Variable & Male $(\mathbf{N}=\mathbf{3 3})$ & Female $(\mathbf{N}=\mathbf{2 8})$ \\
\hline Mean (SD) age & $78(5)$ & $82(6)$ \\
Long-term catheter & II $(33 \%)$ & $2(7 \%)$ \\
IHD & $14(42 \%)$ & $9(32 \%)$ \\
Hypertension & $12(36 \%)$ & $10(36 \%)$ \\
CVA & $5(15 \%)$ & $9(32 \%)$ \\
COPD & $7(21 \%)$ & $2(7 \%)$ \\
Dementia & $7(21 \%)$ & $3(11 \%)$ \\
\hline
\end{tabular}

Abbreviations: CVA, cerebrovascular accident; COPD, chronic obstructive pulmonary disease; IHD, ischemic heart disease; SD, standard deviation.
Table 2 Differences between observed practice versus awareness and knowledge among junior staff members regarding documentation of the catheterization procedure

\begin{tabular}{lll}
\hline Documented parameter & $\begin{array}{l}\text { Observed practice } \\
\text { (\%) }\end{array}$ & $\begin{array}{l}\text { Awareness } \\
\text { (\%) }\end{array}$ \\
\hline Date of catheterization & 78.6 & 100 \\
Time of catheterization & 1.6 & 97.4 \\
Sample sent & 1.6 & 77 \\
Volume drained & 39.3 & 97.4 \\
Urine description & 1.6 & 89.7 \\
Indication & 79 & 100 \\
Aseptic technique & 3.3 & 100 \\
Antibiotic prophylaxis & 40 & 77 \\
\hline
\end{tabular}




\section{Conclusion}

Catheters were placed for indications according to the IDSA guidelines in $89.6 \%$ of patients. ${ }^{1}$ Catheters were placed, but undocumented in $10.4 \%$ of patients. Long-term catheters were in situ preadmission in $21.3 \%$ patients admitted for various medical problems. Doctor and nurse knowledge regarding complications of catheterization was well above average. Responses to the questionnaire demonstrated good awareness of what needed to be documented among staff. However, the practice of documentation did not reflect the awareness demonstrated in the questionnaire and had room for improvement in some aspects.

\section{Disclosure}

The authors report no conflicts of interest in this work.

\section{References}

1. Hooton TM, Bradley SF, Cardenas DD, et al. Infectious Diseases Society of America. Diagnosis, prevention and treatment of catheter-associated urinary tract infection in adults: 2009 International Clinical Practice Guidelines from the Infectious Diseases Society of America. Clin Infect Dis. 2010;50(5):625-663. 


\section{Appendix I}

\section{Data collection sheet}

$\begin{array}{llllllll}\text { Age } & 75-80 & \square & 81-85 \quad \square & 86-90 \quad \square & 91-95 \quad \square & \text { Over } 95 \\ \text { Sex } & \text { Male } \quad \square & \text { Female } \square & & & & & \end{array}$

Hospital Number :

Ward

Primary Diagnosis:

\section{Comorbidity}

IHD

HTN

DM - Type $1 \quad \square \quad$ DM - Type 2

COPD

CVA

Others

\section{Indication for Catheterization}

1. Retention Acute
a. UTI
b. Neuropathic
c. $\mathrm{BPH}$
d. Others

2. Chronic Incontinence

3. Input/Output Chart

Cause

4. Incontinence with Pressure Sore

5. To Obtain Urine Sample

6. Indication for Catheterization Not Clear

7. Admitted with Catheter in Place

\section{Where the Patient was Catheterized}
MAU
A\&E
Ward
Other

\section{Documentation}

Pathway in Notes

Date

Time

Person who Catheterized

Catheter Size

Volume of Urine Drained

Color of Urine Drained

Specimen to Lab

Antibiotic Given

Aseptic Technique

Indication for Catheterization

\section{Documented Not Documented}

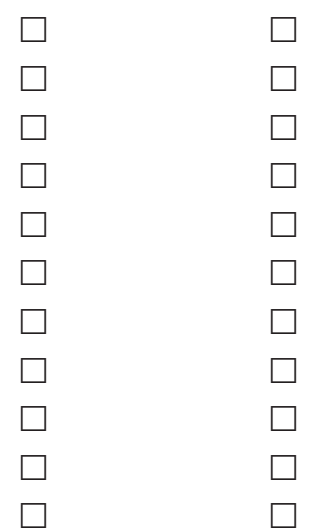




\section{Appendix 2}

\section{Questionnaire survey}

Have you worked in a DME ward? Yes $\square$ No

Dr:

Grade: Foundation year $1 \quad \square \quad$ Foundation year 2

Nurse:

Trained in catheterization: Yes

No

\section{What are the indications for catheterization? (Please tick all that apply)}
a. Acute retention of urine
b. Urinary incontinence (with no comorbidity)
c. Monitoring urine output in ill patients
d. Patient requests
e. To obtain clear urine sample for investigations
f. Incontinent patient with sacral/buttock pressure sore
g. Patient confined to bed and too weak to mobilize to toilet unassisted

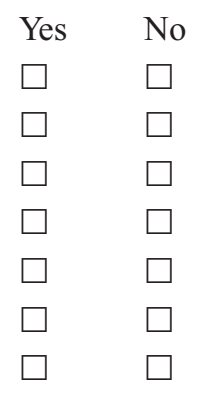

2. Documentation: What information would you document following catheterization? (Please tick all that apply)

$\begin{array}{lll} & \text { Yes } & \text { No } \\ \text { Date } & \square & \square \\ \text { Time } & \square & \\ \text { Samples sent for lab analysis } & \square & \square \\ \text { Volume of urine drained } & \square & \square \\ \text { Description of urine drained } & \square & \square \\ \text { Indication for catheterization } & \square & \square \\ \text { Aseptic technique on catheterization } & \square & \square \\ \text { Difficult catheterization } & \square & \square \\ \text { Antibiotic prophylaxis } & \square & \square\end{array}$

\section{Name three complications of catheterization}

1.

2.

3.

Clinical Audit

\section{Publish your work in this journal}

Clinical Audit is an international, peer-reviewed, open access journal focusing on the processes and outcomes of clinical audit in any area of healthcare. All aspects of patient care are addressed within the journal and practitioners from all disciplines are invited to submit their work. Areas covered include: Publication of audits; How an audit has changed practice; changed patient care; Calls and justifications for new audits. The manuscript management system is completely online and includes a very quick and fair peer-review system, which is all easy to use. Visit http://www.dovepress. com/testimonials.php to read real quotes from published authors. 